\title{
Sensory Gardens: A multidisciplinary effort
}

\author{
Hazreena Hussein ${ }^{a}$, Nik Malik Nik Zainal Abidin ${ }^{\mathrm{b}}$, Zaliha Omar ${ }^{\mathrm{c}}$ \\ aUniversity of Malaya, Fac. of Built Enviro., Dep. of Architecture, Kuala Lumpur 50603 Malaysia \\ bMalik Lip \& Associates, 26A, Persiaran Zaaba, Kuala Lumpur 60000 Malaysia \\ cAl-Bukhary International University, Jalan Tun Razak, Alor Setar 05200 Malaysia \\ reenalambina@um.edu.my
}

\begin{abstract}
This paper engages the users' behaviour, their perceptions of use in sensory gardens and the reality faced by practitioners designing for these gardens, based on case-studies in the United Kingdom. Further investigation will be undertaken at Al-Bukhary International University in Malaysia once the completion of the country's first sensory garden. Interview outcomes showed practitioners concurred on the design aspects that encourage the use of the area while the school staff had no strong views on the aesthetic value. Observation results showed pathway layout encourages behaviour, use and time spent in sensory areas. These outcomes are a significant argument in the conclusion.
\end{abstract}

Keywords: Behaviour; British; Malaysia; sensory garden

eISSN: 2398-4295 @ 2016. The Authors. Published for AMER ABRA by e-International Publishing House, Ltd., UK.. This is an open access article under the CC BY-NC-ND license (http://creativecommons.org/licenses/by-nc-nd/4.0/). Peer-review under responsibility of AMER (Association of Malaysian Environment-Behaviour Researchers), ABRA (Association of Behavioural Researchers on Asians) and CE-Bs (Centre for Environment-Behaviour Studies), Faculty of Architecture, Planning \& Surveying, Universiti Teknologi MARA, Malaysia.

https://doi.org/10.21834/ajbes.v1i1.18 


\subsection{Introduction}

The material for this paper comes mainly from a Ph.D. work, carried out in the United Kingdom. Following Hussein's (2009a) research on the design and use of sensory gardens, the researcher focuses on the future challenges how research and practice could be engaged in creating for outdoor multi-sensory environments in both British and Malaysian context. This study carried out for Al-Bukhary International University (AIU) in collaboration with Malik Lip \& Associates aims to improve the outdoor environment on school grounds, focusing on sensory gardens as an educational resource to demonstrate how students' behaviours and learning skills could be enriched. Hussein (2009a) discovered that there are many precedents for sensory environments; however, there was not much thought given to the design of these environments. Thus, the environment and behaviour research should be in demand that includes systematic investigation of the relationships between the environment and human behaviour, and their implication for the design of sensory gardens. Currently, research into sensory gardens, focusing on children with exceptional needs is still new in Malaysia. Here, the research collaboration learns further from the successes and failures of the case studies selected in the UK, while sharing its experiences, so as to improve the design of sensory gardens in Malaysia in the future. The paper has also informed the construction of the first sensory garden: 'Syarifah Rokiah Knowledge Centre' in AIU, Kedah as an effort to provide a sensory environment for learning.

\subsection{Literature Review}

Highlight on the main literatures reviewed Sensory gardens have evolved gradually from the traditional concept of a 'garden for the blind' to sensory landscapes (Hussein, 2011). The idea is to integrate green areas that will encourage sensory stimulation, physical mobility and social skills (Hussein, 2009a) as well as health improvements (Vries, 2010), environmental education (Building Bulletin 102, 2008), emotional growth and mental development (Maller and Townsend, 2006). 'Multi-sensory environment' (Pagliano, 1999) raised some questions: Are not all gardens sensory? Of what is a sensory garden composed? How do people use the sensory gardens? The initial literature review by Hussein (2009a) revealed a lack of rigorous research on sensory gardens, so the best approach would be to visit places that claim to have such gardens.

Preliminary interviews were carried out with experts, practitioners and school staff, followed by observations of how children with specific educational needs used these gardens. This fieldwork would support the case studies selection and help prepare for the data collection stage. Three main issues arose from the investigation: Firstly, concerns the design. Often, a creator's biggest mistake is in presuming the users' needs. Creators should understand how users behave, use and engage with the garden features. For example, while a creator may be aware that water is a significant feature of a garden - in some sensory gardens, the water is not easily accessible to all. Secondly, associated with the maintenance. Poorly maintained gardens will decrease concerning their sensory impact and, therefore, will not entice people to visit. Thirdly, relates to the lack of design guidelines for sensory gardens. Why do problems still exist in sensory gardens even though they designed?

The researcher conducted an interview with Jane Stoneham, the Director of Sensory Trust. Stoneham stated that although there are publications on multi-sensory environments, for 
example, Snoezelen (Cavet and Mount, 1995) and anthropometrics (Harris and Dines, 2005); the design of sensory gardens currently relies on the experience and the attitude of creators. This idea supported interviews with practitioners in the UK and Malaysia. They note that there is a lack of detailed guidelines available when designing sensory gardens for people with disabilities.

\subsection{Methodology}

This research constructed a methodology based on Moore and Cosco's research (2007) on inclusive parks. The researcher further developed it in the context of a sensory garden. Two sensory garden sites were selected: Royal School for the Deaf and Communication Disorders, Manchester (RSDCD) and Lyndale School, Liverpool (LS).

The data collection started with an interview with the practitioner. This was to find out the intentions of, and the design process undertaken by them and the challenges that they had to deal with. Subsequently, interviews with teachers and therapists were conducted to explore the benefits in having a sensory garden as part of a school's education facility. Then, observations of on-site activities were recorded in May and July, for seven consecutive working days each month from $8.30 \mathrm{am}$ to $3.30 \mathrm{pm}$. The chosen period of observation was to ensure that the daily variations in behaviour could be observed.

There are three research limitations: Firstly, the interviews with students were not undertaken extensively. The researcher found it was especially difficult to get first-hand information from them because of the communication difficulties. Secondly, was the duration of data collection. The actual period of data collection for the two special schools was just five weeks to coincide with the school term periods.

Furthermore, the researcher thought the months of May and July offered the best outdoor conditions in the UK. Thirdly, the similar methodology could be further explored in a Malaysian context. To date, the researcher only conducted an interview with the practitioner who designed the 'Syarifah Rokiah Knowledge Centre' as its garden is under construction. However, the interview result can be used to fulfil part of the research objectives. Further investigation scheduled to be carried out upon the completion of the sensory garden.

\subsection{Results and Discussions}

The sensory garden of RSDCD, designed in 2000 by Sue Robinson, a practitioner from Stockport Metropolitan Borough Council. According to Robinson, besides carrying out site survey and analysis, she had close collaboration with staff and students. The key principles are to create a multi-sensory garden, which would cater for a wide variety of user capability; to offer an attractive location to young people while providing varied sensory perceptions and good educational value. The design objectives were to provide a variety of different forms, textures, colours, shade, touch and sound; to accommodate access from all directions to this centrally located site; and to achieve maximum potential by providing a series of linked mini gardens. The main challenge was to design for and accommodate an extensive range of user capabilities and needs.

The planning and design work of the sensory garden in LS was prepared and completed in September 2005 by a practitioner, Mark Boothroyd of Groundwork Wirral. Similar to the first 
case study, Boothroyd had also done prior research, including having a consultation with the school community. During the design stage, collage work with staff and students in the school produced to show the outdoor environment they wanted. The key principles are to transform the sloping grounds into a stimulating environment where the children could explore, with some degree of independence, allowing for maximum enjoyment to enhance their learning experience through natural features. The design objectives were to make the area accessible; to maximize the potential of the site and highlight the principles that govern the indoors to the outdoor environment. The main challenges were to have a sensory garden on a limited fund, the technical use of a water feature and maintenance. Boothroyd also needed to develop an understanding of the users' needs as the scope of this work ranged from a conceptual development to the master plan.

The interview results: Practitioners of the two schools' garden agreed on the same design aspects that encourage the use of the area in a sensory garden. These are users' accessibility, aesthetic value, maintenance, planting, the quality of sensory equipment, safety and the spatial location of the garden to the site context. Meanwhile, the teachers and therapists in both schools concurred with many of these aspects, highlighting that users' accessibility, maintenance, planting, the quality of sensory equipment, safety and the spatial location of the garden may greatly enable the use of the area. However, unlike the practitioners, half of these respondents held no firm views on how the aesthetic value relates to the use of the garden area. This was because some of their students were partially sighted and visually impaired.

The observation results: It was surprising to discover that students of both schools use the sensory gardens in all types of weather. For example, on every day of the observation period at the RSDCD, a wheelchair student and her teaching assistant would use the sensory garden for between 30 minutes and an hour from midday. No matter whether it was a sunny, rainy or windy day, she would be wheeling in the garden. Another notable incident took place at the LS when a young boy and his teaching assistant were taking a leisure stroll in the sensory garden. As they reached the boardwalk underneath a shady canopy, the assistant jumped up and grabbed a branch. The boy looked at her, puzzled as to why she had done that. 'I have a surprise for you... are you ready?' She asked as he held the rope railing and jumped with excitement. Keeping a good grip on the branch, the assistant shook it hard, causing drops of rainwater to fly from the leaves. The boy was so surprised that he let go of the rope railing, lifted his arms and turned his face to the sky so he could feel the water falling on it. At a time, he even opened his mouth to taste it. This simple setting enabled the teaching assistant and student to laugh together as they both got wet. It proved the point that sometimes the simplest ideas are the best. From the observation results, it showed that the layout of the circulation network enables user behaviour and use of the area. Users also spent a longer time in areas where sensory was emphasised, rather than aesthetic value.

There was a notable difference between how the practitioners, teachers and therapists anticipated users would behave and what was recorded during the observation periods. Some of the similarities and differences summarized based on the case studies:

\subsection{RSDCD}

The interviews and observations suggested that well-planned paths are highly significant and would lead to high usage. A good pathway network should provide clear links between school buildings and the garden, and should enable easy circulation (see Figure 1). 


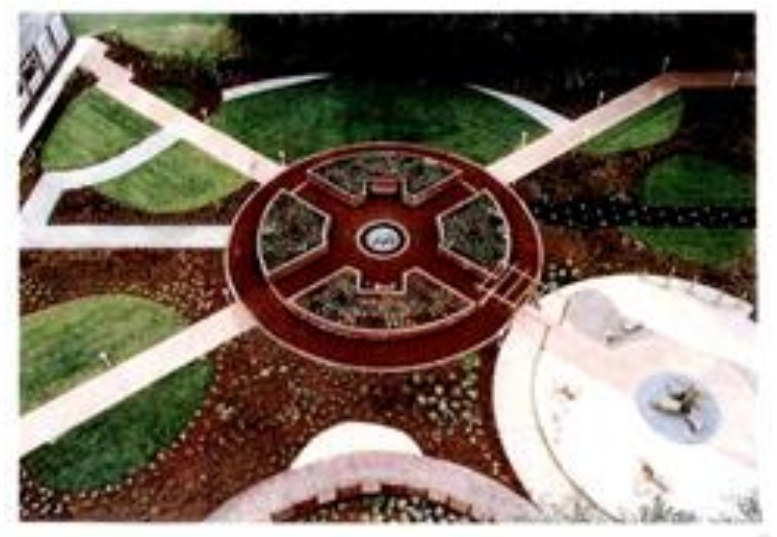

Figure 1: Accessibility and variety of pathways

(Source: Author)

Many interviewees thought that planted shrubs around a water feature acted as a barrier. In practice, though, many users spent a lot of time enjoying this feature. The inclusion of shrubs does not seem to have affected the level of usage (see Figure 2).

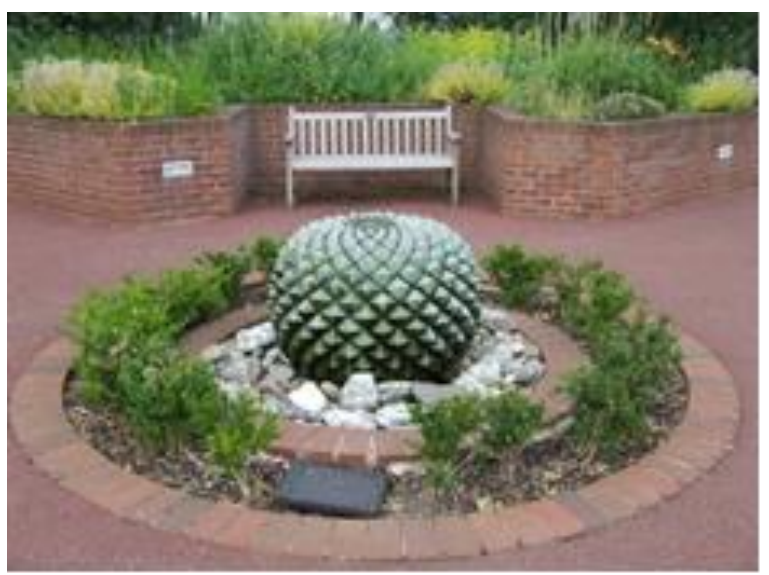

Figure 2: Water feature

(Source: Author)

The interviews and observations suggested that the least used features were the Vaporised Trail (see Figure 3) and Exploraway (see Figure 4). This is due to the unsuitability of the surface material for many users. Although the practitioner assumed that the Vaporised Trail are difficult for users to utilize, in reality, some users seen stepping on and over the blocks as they passed through the garden. Ironically, the Exploraway - so called because the practitioner originally intended for its surface to be much bumpier - offers less of a challenge than the other paths. 


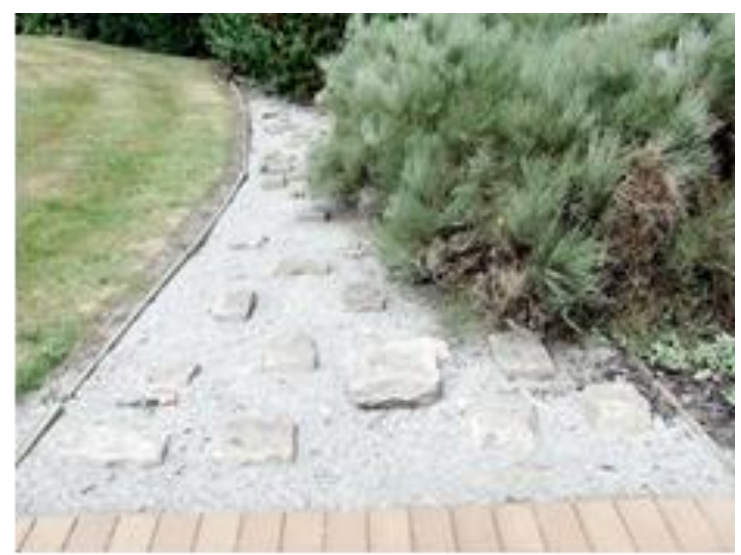

Figure 3: Vaporised Trail

(Source: Author)

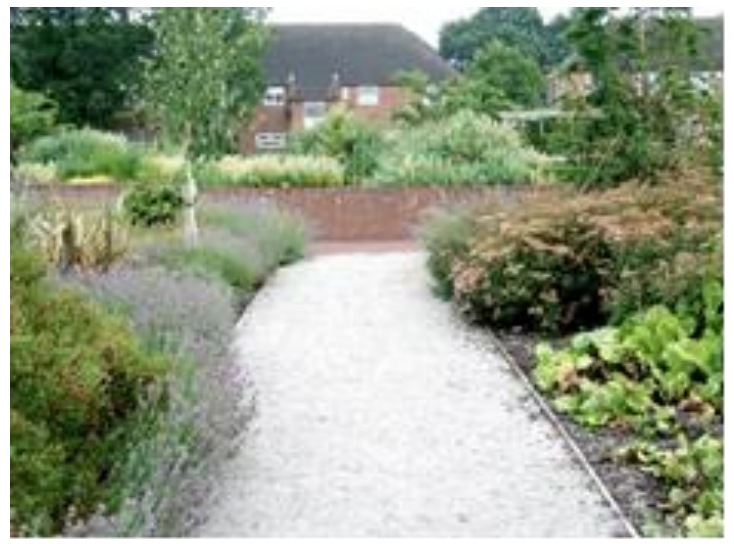

Figure 4: Exploraway

(Source: Author)

The practitioner predicted that the musical area would be the most popular and the observation results confirmed this to a certain extent. However, the school staff thought the musical instruments were inaccessible, lacked variety and did not motivate users because the feature does not make any sound (see Figure 5).

The school staff stated that the raised planters were inaccessible to students in the wheelchair due to its width (see Figure 6). However, during the observation period, while students on bicycles were passing by the garden, they were touching the moss on this feature. In fact, this proved to be the most popular feature regarding the average time spent there by users. 
Hussein, H., et.al. / Asian Journal of Behavioural Studies, AjBeS, Maiden, 1(1), May/June 2016 (p.31-40)

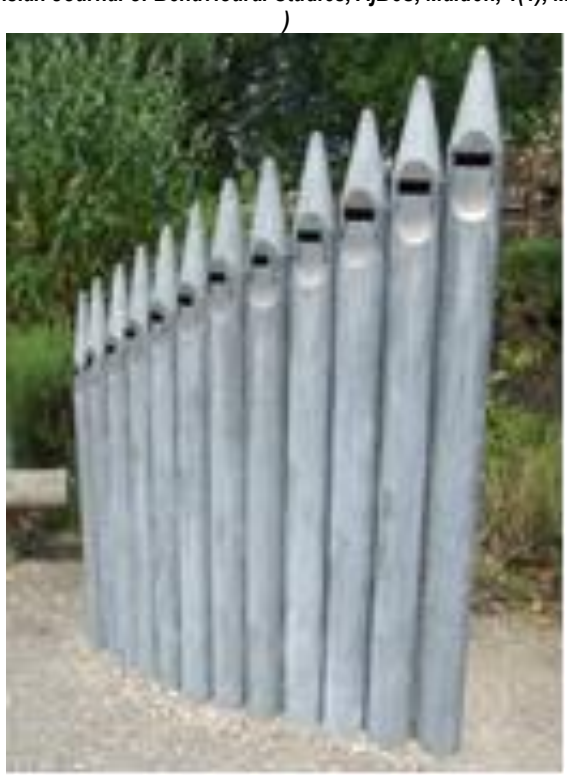

Figure 5: Musical pipes

(Source: Author)

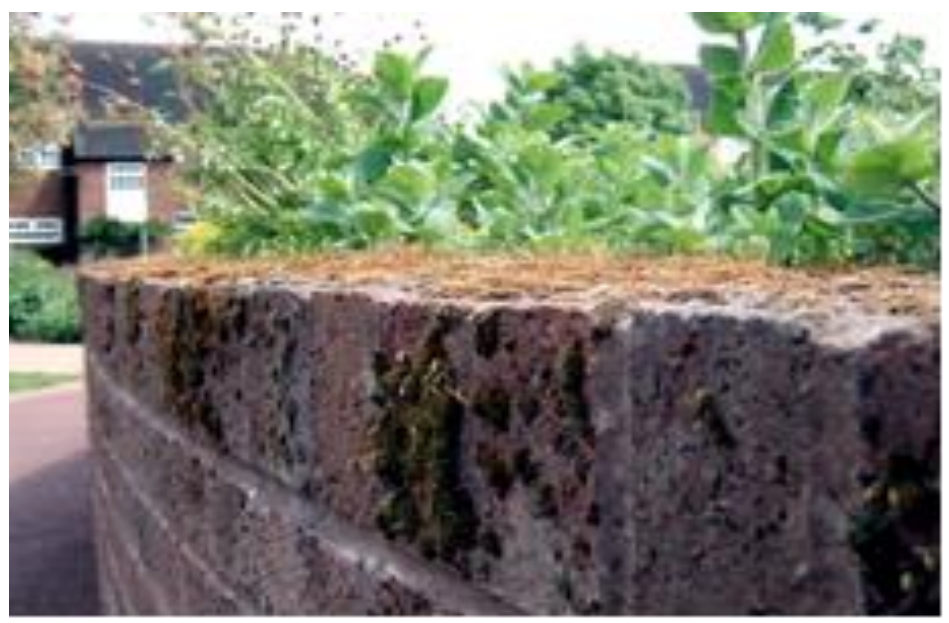

Figure 6: Raised planter with moss (Source: Author)

\subsection{LS}

Both sets of results showed that sudden ending pathways were used the least. Although many students appreciated the sound stimuli at the end of the boardwalk, this caused them to linger, creating a bottleneck of users in one area (see Figure 7). 


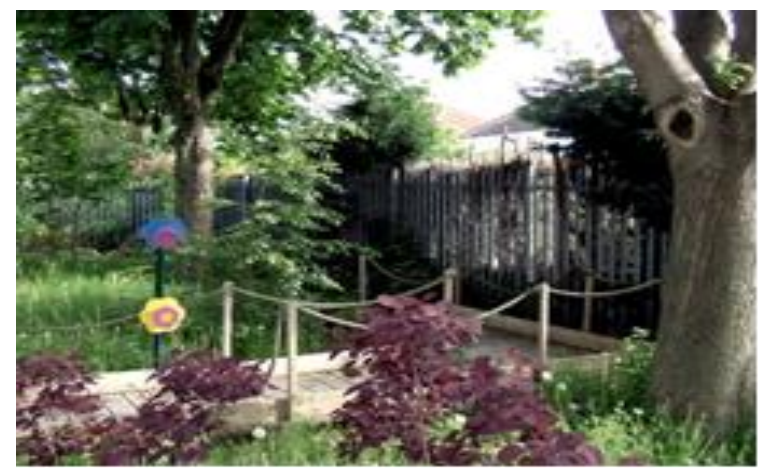

Figure 7: Path circulation that does not allow a flow of user (Source: Author)

The practitioner and teachers thought that the water feature was the most successful concerning the frequency of use. However, the observation results showed that this feature had the second lowest number of users. This is probably due to the slippery surface at the boardwalk, and inaccessible raised beds (see Figure 8).

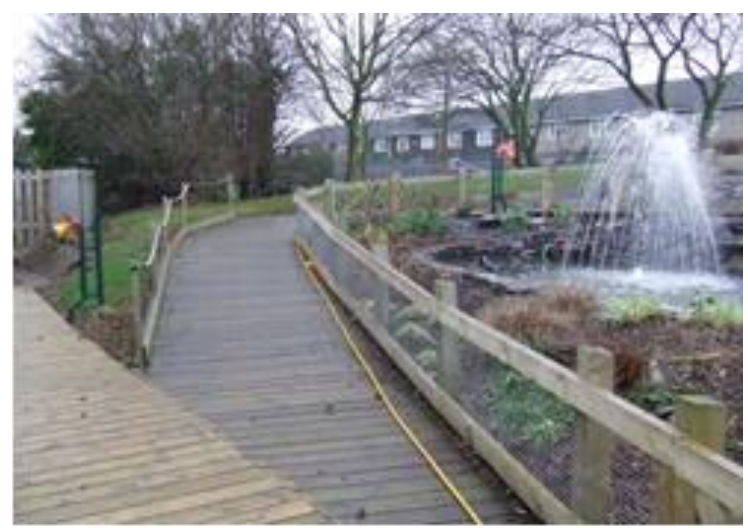

Figure 8: Water fountain

(Source: Author)

\subsection{Conclusion}

Pathway layout has a strong bearing on users' behaviour and use of the area in the sensory garden. Pathway network that links the garden to the rest of the area will provide users with easy access to the functional features hence, will encourage more users to enjoy the sensory benefits of these gardens. This finding echoed research on inclusive parks undertaken by Moore and Cosco (2007), which showed that a highly positive feature and one was the most popular among the users, was a wide pathway that gave access to the facilities that were readily accessible. 
Areas that focus on sensory rather than aesthetic appear to attract the greatest number of users, and they tend to spend a longer time here than in other areas. Thus, to identify and suggest how 'sensory value' could be integrated into the design and implemented in practice, would be a useful contribution to new knowledge. What practitioners should be designing is something more like a 'sensory trail'. The fact that users can get access to and engage with the features is the key point when designing for these gardens. It is more to do with where the functional features located rather than what they are.

This research has raised some valuable points concerning the assumptions that many people make about sensory gardens. There was often a stark difference between what the practitioners and teachers thought would be popular and what worked well in reality. Practitioners should visit existing sensory environments to observe the usage before starting a project (Farrer, 2008), to help them understand the engagement that occurs between users and their surrounding environment (Nebelong, 2008). Of course, practitioners have limited time to set observing these environments, which brings us to the final point: the need for solid best practice guidance on sensory gardens. Only once we have well researched, reliable design guidance on these environments will start to see the standard of sensory gardens raised to a consistently high level.

New directions for further research at the AIU where the first sensory garden is undergoing construction. It would be interesting to examine the design and use in a Malaysian context. The result of future research would produce further knowledge into how the composition of the features and the spatial design of the sensory garden would enable users' engagement and usability of the garden. Thus, additional recommendations and improvements for future use, planning and the design of sensory gardens could be suggested.

\section{Acknowledgement}

The researcher wishes to thank Professor Catharine Ward Thompson and Professor Peter Aspinall of the Edinburgh College of Art; and Jane Stoneham of the Sensory Trust. Special thanks to Funds for Women Graduates for making the data collection achievable and lastly, all respondents, for their participation in this research.

\section{References}

Building Bulletin 102 (2008). Designing for disabled children and children with special educational needs. The Stationary Office. Norwich: HMSO.

Cavet, J. and Mount, H. (1995). Multisensory environments. In J.Hogg and J.Cavet (Eds.), Making leisure provision for people with profound and multiple learning disabilities (pp.67-85). London: Chapman and Hall.

Farrer, N. (2008). 'Golden Moments' by Tim Coulthard. Landscape Design: Journal of Landscape Institute, No. 53, August 2008, 10-20.

Harris, C. and Dines, N. (2005). Time-saver standards for landscape architecture. McGraw-Hill.

Hussein, H. (2011). The influence of sensory gardens on the behaviour of children with special educational needs. Asian Journal of Environment - Behaviour Studies, 2(4), 77-93. 
Hussein, H. (2009a). Therapeutic intervention: Using the sensory garden to enhance the quality of life for children with special needs. Unpublished Doctorial. Edinburgh College of Art.

Hussein, H. (2009b). Sensory garden in special schools: The issues, design and use. Journal of Design and Built Environment, 5, 77-95.

Maller, C. and Townsend, M. (2006). Children's mental health and wellbeing and hands-on contact with nature. International Journal of Learning, 12(4), 359-372.

Moore, R.C. and Cosco, N.G. (2007). What makes a park inclusive and universally designed? A multi-method approach. In Thompson, C.W. and Travlou, P. (Eds.), Open space: People space (pp.85-110). London: Taylor \& Francis.

Nebelong, H. (2008). A sense of place: Improving children's quality of life through design. Green Spaces, Issue 45, May, 20-24.

Pagliano, P.J. (1999). Multi-sensory environment. London: David Fulton Publishers.

Vries, S.D. (2010). Nearby nature and human health: Looking at mechanisms and their implications. In Thompson, C.W., Aspinall, P. and Bell, S. (Eds.) Open space: People space 2 (pp.75-96). Oxon: Routledge. 